Port Acadie

Revue interdisciplinaire en études acadiennes

An Interdisciplinary Review in Acadian Studies

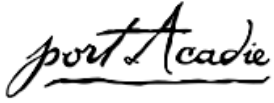

\title{
La politique patrimoniale de la municipalité de Clare
}

\section{Delphis Comeau}

Numéro 10-11-12, automne 2006, printemps-automne 2007

Le patrimoine religieux de la Nouvelle-Écosse : signes et paradoxes en Acadie

URI : https://id.erudit.org/iderudit/018643ar

DOI : https://doi.org/10.7202/018643ar

Aller au sommaire du numéro

Éditeur(s)

Université Sainte-Anne

ISSN

1498-7651 (imprimé)

1916-7334 (numérique)

Découvrir la revue

Citer cet article

Comeau, D. (2006). La politique patrimoniale de la municipalité de Clare. Port Acadie, (10-11-12), 239-242. https://doi.org/10.7202/018643ar

\section{Résumé de l'article}

Il y aurait 51 municipalités en Nouvelle-Écosse qui ont un plan de protection des propriétés patrimoniales. La municipalité de Clare n’en fait pas encore partie. Elle a cependant fait des démarches en ce sens et l'auteur en donne un bref aperçu. Il fait ensuite quelques commentaires sur les problèmes liés à l'entretien des églises et sur les normes qui les régissent. 
TROISIÈME PARTIE : L'AVENIR DU PATRIMOINE RELIGIEUX

QUAND L'ÉTAT S'ENGAGE

\section{La politique patrimoniale de la municipalité de Clare}

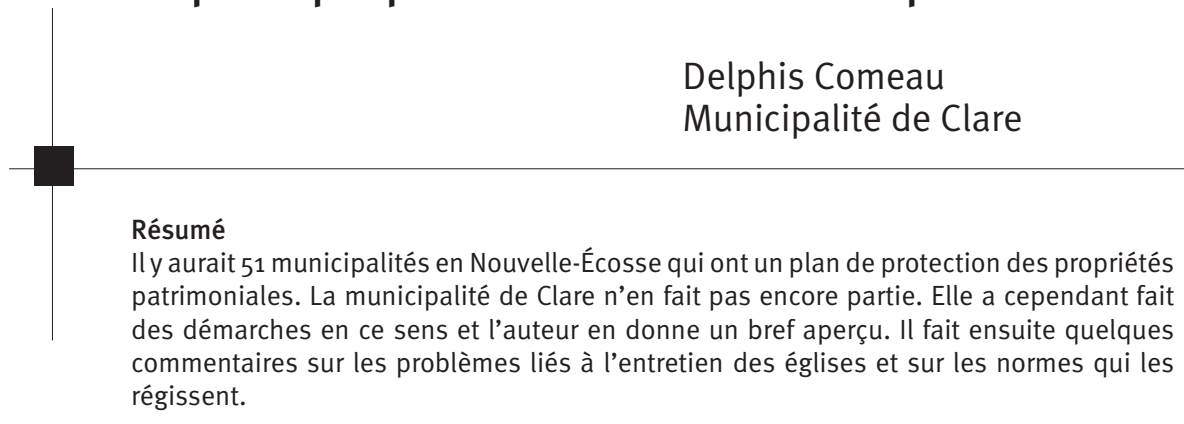

La municipalité de Clare est la seule municipalité de la NouvelleÉcosse qui fonctionne en français et dont les réunions du conseil se déroulent en français. Comme on l'a déjà avancé ici, il y a cinquante-etune municipalités en Nouvelle-Écosse qui ont un plan de protection des propriétés patrimoniales et quatre qui n'en ont pas. À ce moment-ci, il est vrai que la municipalité de Clare n'est pas impliquée. Elle a cependant fait des démarches en ce sens. En 1993, elle a embauché deux personnes et il y a eu de fréquentes discussions avec la province de la NouvelleÉcosse. Ces deux personnes ont fait des recherches sur cent dix-huit maisons construites avant 1914. Il existait alors un comité; je pense que Gérard d’Entremont en était, avec quelques conseillers. À cette époque, c'était nouveau et les gens pensaient que, en inscrivant leurs propriétés, ils obtiendraient de l'argent. Mais ce qui les dérangeait surtout, c'étaient les restrictions que la municipalité aurait pu leur imposer concernant les changements à apporter à leurs maisons. Alors nous n'avons pu inciter personne à inscrire sa propriété en tant que propriété historique dans Clare.

Depuis ce temps-là, nous avons malgré tout - soit dit sans offusquer celle qui m'a précédé -, quatre propriétés qui sont désormais inscrites au niveau provincial : d'abord, à la Pointe-de-l'Église, il y a l'église SainteMarie, la maison Isaac-LeBlanc et l'ancien presbytère (aujourd'hui la maison d'un fils d'Arcade à Joe Belliveau) et, à Corberrie, l'église SaintJean-Baptiste. Dans tous ces cas, il y a eu des discussions et, là encore, on cherchait à voir s'il y avait possibilité d'obtenir de l'argent. La même 
expérience s'est répétée l'année dernière pour l'église de Saint-Bernard, pour laquelle on recherchait une désignation du gouvernement fédéral; cette église n'est pas en très bon état et les paroissiens auraient aimé trouver des fonds pour la conserver. Par ailleurs, au niveau local, la municipalité de Clare a désigné le premier cimetière acadien qui se trouve à la Pointe-à-Major comme site patrimonial le 5 septembre $1993^{1}$. C'est, pour le moment, le seul site inscrit au registre municipal.

Alors, ce sera le rôle de ceux d'entre vous qui travaillez auprès des conseils paroissiaux de leur expliquer que les désignations ne sont pas là uniquement pour apporter de l'argent, mais qu'elles sont faites pour préserver le patrimoine religieux. La municipalité de Clare est certainement prête à reprendre ce dossier. Le préfet et certains conseillers en seraient très heureux : si quelqu'un d'entre vous voulait en prendre l'initiative, nous serions prêts à mettre sur pied un nouveau comité et à relancer ses activités, parce que nous pensons c'est un engagement valable.

Si vous me le permettez, j'aimerais maintenant faire quelques commentaires sur les interventions entendues pendant ce colloque. Hier, Jean-Pierre Pichette, dans son discours d'ouverture, a indiqué que, d'ici quinze, vingt ou vingt-cinq ans, il y aurait certainement des décisions à prendre dans le domaine du patrimoine religieux et que ce dernier pourrait faire face à une crise. Sans parler de crise, je pense qu'il y aura beaucoup de changements, par exemple au chapitre de l'entretien et des réparations. Vous avez entendu ces derniers jours des conférenciers de la baie Sainte-Marie, de Chéticamp et d'Arichat vous raconter que, autrefois, on pouvait bâtir une église, comme notre église Sainte-Marie, en l'espace de deux ans et que les entrepreneurs et leurs ouvriers n'avaient pour toute formation qu'une quatrième, une cinquième ou une sixième année d'études. Actuellement, la municipalité est en train de construire ici une bâtisse dont les charpentiers ont les formations les plus modernes au monde; commencée il y a déjà huit mois, elle n'est pas encore finie. C'est que, maintenant, c'est le gouvernement fédéral qui détermine les normes pour la construction au Canada. Chaque province accepte le code fédéral, en l'occurrence le code du bâtiment, et ensuite la province donne la responsabilité aux municipalités de gérerce domaine-là. Vous savez qu'une toiture pour une maison ou une église dure à peu près vingt-cinq ans. Pour ce faire, il y a vingt-cinq ans, une dizaine de travailleurs de Clare, reconnus comme charpentiers, se faisaient des échafaudages, montaient sur le toit et remplaçaient la toiture et les travaux s'achevaient ainsi. Aujourd'hui -

1. Précision fournie par Raymond LeBlanc, de la Société historique acadienne de la baie Sainte-Marie. 
et je pense que l'église Sainte-Marie a connu cette difficulté il y a deux ou trois ans - il faut recourir à des experts : des experts d'Halifax sont donc venus ici et puis cela a coûté, juste pour construire les échafaudages pour se rendre au toit, quatre-vingt mille dollars. Avec de tels changements, je suis convaincu que, selon le code municipal - adopté par la province et conçu par le fédéral -, il n'y a pas un ingénieur en Nouvelle-Écosse qui dirait que nos églises, qu'elles soient ici ou à Chéticamp, ou à Arichat, devraient être encore debout; mais pourtant elles le sont toujours.

Ce n'est pas tout. Récemment, la province a forcé les municipalités à établir un poste d'inspecteur des dangers d'incendie. Alors, l'année dernière, cet inspecteur a visité tous les endroits publics, les édifices de la Légion canadienne, les clubs sociaux, etc.; cette année, c'est le tour des églises. Notre inspecteur est en train de faire son plan et s'apprête à examiner les églises. On peut déjà prévoir que ce sera très coûteux pour certaines églises : pensons simplement aux enseignes de sorties et aux autres dispositifs de sécurité qu'il faudra installer dans ces édifices qui peuvent contenir par exemple quatre cents personnes et qui, à l'occasion de funérailles, en accueillent mille. De même, c'est la coutume à la baie Sainte-Marie, à Noël, de décorer l'église avec des arbres de Noël, des sapins véritables qui sèchent rapidement; sans pointer du doigt aucune église, on sait qu'on y trouve parfois des sapins tout proches de la crèche et des chandelles et que le règlement interdira dorénavant les sapins naturels dans les églises.

Ce ne sont là que quelques exemples des changements qui viennent effectivement des municipalités, mais qui leur sont imposés par les paliers de gouvernement supérieurs. Alors, si les projets d'entretien et de réparation des églises s'annoncent très coûteux, je crois qu'il faut dès maintenant commencer à élaborer des plans stratégiques, au niveau des groupes paroissiaux et avec l'aide de la municipalité, pour les mener à terme. Il y a une dizaine d'années, le gouvernement fédéral, en partenariat avec les provinces et les municipalités, avait subventionné de grands travaux dans son programme d'infrastructure. Ainsi, dans un projet donné, la municipalité fournissait le tiers des coûts. tandis que le fédéral et la province assumaient les deux autres tiers. À cette époque, on avait accepté dans ce programme les gros travaux effectués aux églises de Saulnierville, de la Pointe, des Concessions et de Saint-Alphonse. Depuis trois ou quatre ans, le gouvernement a changé de direction. L'heure est maintenant aux " projets verts » : il y a de l'argent pour les systèmes d'aqueduc et d'égoûts, la décontamination des terrains, la valorisation de l'environnement, mais il n'y a plus rien pour la réparation des églises ou même des salles de pompiers. À cela s'ajoute la dépopulation de notre municipalité : on estime que, depuis trois ans, Clare a perdu environ six 
cents habitants; trois cents sont morts et trois cents autres sont partis à Halifax ou en Alberta; la municipalité a par conséquent moins de revenus et il en va de même dans d'autres domaines. C'est pourquoi je pense qu'il faut tous nous concerter et travailler ensemble. 